\title{
CÁC YẾU TỐ TÁC ĐộNG ĐẾN LợI NHUẬN CỦA NGÂN HÀNG THƯƠNG MẠI CỔ PHẦN VIỆT NAM
}

\author{
NGUYỄN THI THÚY HẠNH \\ Truờng Đại học Đà Nã்ng \\ ntthanh296@gmail.com
}

Tóm tắt. Nghiên cứu phân tích các nhân tố tác động đến lợi nhuận của ngân hàng thương mại cổ phần Việt Nam giai đoạn 2009-2016. Kết quả nghiên cứu cho thấy lợi nhuận của ngân hàng bị ảnh hưởng bởi các nhóm nhân tố bên trong và bên ngoài ngân hàng. Nhân tố bên trong gồm qui mô, rủi ro tín dụng, thu nhập ngoài lãi, chi phí ngoài lãi, tỷ lệ vốn chủ sở hữu trên tổng tài sản. Nhân tố bên ngoài gồm tăng trưởng kinh tế và lạm phát. Sử dụng hồi qui dữ liệu bảng, kết quả cho thấy qui mô, thu nhập ngoài lãi, chi phí ngoài lãi, tỷ lệ vốn chủ sở hữu trên tổng tài sản, tăng trưởng kinh tế và lạm phát có tác động dương ý nghĩa đến lợi nhuận của ngân hàng thương mại. Từ đó, nghiên cứu cũng khuyến nghị các giải pháp nhằm gia tăng lợi nhuận của ngân hàng thương mại Việt Nam trong thời gian sắp tới.

Từ khoá: ngân hàng, lợi nhuận, nhân tố, qui mô, tài chính

\section{FACTORS AFFECTING THE PROFITABILITY OF COMMERCIAL BANKS IN VIET NAM}

\begin{abstract}
The present paper seeks to examine the deteminants of Vietnam banks profitability during the period 2009-2016. The empirical findings suggest that bank profitablity have been impacted by internal factors and external factors. Internal factors includes size, credit risk, non-interest income, non-interest expense, ratio of stockholder's capital per total assets. External factors concludes economic growth and inflation. Using the panel data regression, the results provided that size, credit risk, non-interest income, non-interest expense, ratio of stockholder's capital per total assets, economic growth and inflation have a positive significant impact on bank profitability. Therefore, the papers suggest some solutions to increase profitability of the commercial bank in Vietnam in the future.
\end{abstract}

Keywords: bank, profitability, factor, size, finance

\section{GIỚI THIẸU}

Ngân hàng đóng vai trò trung gian tài chính quan trọng trong nền kinh tế, tập trung các nguồn vốn nhàn rỗi để đáp ứng nhu cầu vốn của các tổ chức, cá nhân. Do đó, sức khỏe tài chính của ngân hàng rất quan trọng đối với nền kinh tế của đất nước. Bên cạnh đó, mục tiêu hoạt động của ngân hàng thương mại cổ phần chính là lợi nhuận. Các nghiên cứu về các nhân tố tác động đến lợi nhuận của ngân hàng là rất cần thiết không chỉ đối với các nhà quản trị ngân hàng mà còn đối với cơ quan quản lý nhà nước như ngân hàng nhà nước, chính phủ. Hiểu về các nhân tố này sẽ giúp ích cho các cơ quản quản lý nhà nước và các nhà quản lý ngân hàng ban hành các chính sách phù hợp góp phần gia tăng lợi nhuận của hệ thống ngân hàng.

Trong giai đoạn 2009 đến nay, hệ thống ngân hàng thương mại đã có những thay đổi như nợ xấu ngân hàng tăng, giảm qua các năm, năm 2009: 2,05\%, năm 2010: 2,16\%, năm 2011:3,07\%, năm 2012: 4,08\%, năm 2013: 3,61\%, năm 2014: 3,25\% (Cẩm An, 2015); những ngân hàng yếu kém không thể cạnh tranh và tồn tại bị mua bán và sát nhập với các ngân hàng lớn trong nước như ngày 7/8/2012, NHNN đã ký và ban hành quyết định số $15559 / \mathrm{Q} Đ-\mathrm{NHNN}$ chấp nhận sáp nhập HBB vào SHB hay NHNN đã lần lượt ra quyết định mua bắt buộc 3 NHTM CP với giá 0 đồng gồm NH xây dựng Việt Nam, NH đại dương, GP Bank (Nguyễn Xuân Thành, 2016). Để quản lý hoạt động và bảo đảm an toàn của hệ thống ngân hàng, cơ quan quản lý nhà nước đã ban hành rất nhiều qui định về hoạt động của hệ thống ngân hàng thương mại như vốn pháp định, tỷ lệ bảo đảm an toàn trong hoạt động của các tổ chức tín dụng, phân loại nợ...Cụ thể: Nghị định số 141/2006/NĐ-CP quy định bắt buộc các NHTM CP phải tăng vốn điều lệ lên 3000 tỷ đồng cuối năm 2010 ( Chính phủ, 2006); Thông tư số 36/2014/TT-NHNN qui định tổ chức tín dụng phải duy trì tỷ lệ an toàn vốn tối thiểu riêng lẻ $9 \%$ (Ngân hàng nhà nước, 2014) đến năm 2016, tỷ lệ an toàn vốn tối thiểu giảm xuống còn $8 \%$ (Ngân hàng nhà nước, 2016). Đây cũng là giai đoạn mà nền kinh tế Việt Nam có những biến động 
mạnh như lạm phát tăng mạnh từ 6,52\% năm 2009 đến 18,58\% năm 2011; tổng sản phẩm trong nước theo giá thực tế có xu hướng tăng mạnh, năm 2016 đạt 4.502 .733 tỷ đồng, tăng $150 \%$ so với năm 2009 ( Tổng cục thống kê Việt Nam, 2017).

Tuy nhiên, hiện chưa có nghiên cứu nào tiến hành phân tích những nhân tố ảnh hưởng đến lợi nhuận của ngân hàng thương mại cổ phần Việt Nam trong giai đoạn này. Chính vì thế, nghiên cứu sẽ lấp khoảng trống nghiên cứu về thực tiễn và xác định những nhân tố tác động đến lợi nhuận của ngân hàng thương mại cổ phần trong giai đoạn 2009 đến 2016. Từ đó, nghiên cứu sẽ đề xuất một số giải pháp nhằm gia tăng lợi nhuận của hệ thống ngân hàng thương mại cổ phần Việt Nam trong thời gian sắp tới.

\section{TỔNG QUAN TÀI LIỆU NGHIÊN CÚU}

Lợi nhuận cũng là căn cứ để đánh giá năng lực về nhân sự, năng lực về tài chính, năng lực quản lý và điều hành hoạt động kinh doanh của ngân hàng. Lợi nhuận tác động đến tất cả mọi hoạt động của ngân hàng, nó ảnh hưởng trực tiếp đến tình hình tài chính của ngân hàng, là điều kiện quan trọng đảm bảo cho khả năng thanh toán của ngân hàng. Lợi nhuận ngân hàng thường được đo lường bằng $\mathrm{ROA}$ và $\mathrm{ROE}$. Tuy nhiên, theo các nghiên cứu đi trước, lợi nhuận ngân hàng được đo lường tốt nhất bằng ROA vì ROA phản ảnh khả năng quản lý tài chính ngân hàng và nguồn đầu tư để tạo ra lợi nhuận, ROA phụ thuộc vào các chính sách của chính ngân hàng cũng như những nhân tố bên ngoài liên quan đển nền kinh tế và điều tiết của nhà nước ( Ben Naceur và Goaied (2009); Sufian và Chong (2008). Trong khi đó, ROE phản ảnh hiệu quả sử dụng vốn chủ sở hữu của ngân hàng. Do đó, nghiên cứu lựa chọn ROA để đo lường biến phụ thuộc lợi nhuận.

Các nghiên cứu đi trước đã chỉ ra những nhân tố tác động đến lợi nhuận của NHTM gồm nhân tố bên trong và bên ngoài. Các nhân tố bên trong bao gồm qui mô, rủi ro tín dụng, thu nhập ngoài lãi, chi phí ngoài lãi, tỷ lệ vốn chủ sở hữu trên tổng tài sản. Các nhân tố bên ngoài được xác định gồm tăng trưởng kinh tế và lạm phát.

\section{Các nhân tố bên trong}

Qui mô ngân hàng quyết định trực tiếp đến sự tồn tại và phát triển hoạt động kinh doanh của các ngân hàng thương mại. Miller và Noulas (1997), Athanasoglou và công sự (2006) chỉ ra rằng sự gia tăng quy mô ngân hàng có thể tiết kiệm được một phần nào chi phí khi hệ thống ngân hàng mở rộng, sự gia tăng quy mô vốn tác động cùng chiều đến lợi nhuận ngân hàng ở một mức độ nhất định.

Bên cạnh đó, cấp tín dụng là hoạt động chính ở các ngân hàng thương mại do đó chất lượng tín dụng sẽ ảnh hưởng đến kết quả hoạt động kinh doanh của ngân hàng. Khi tỷ lệ nợ quá hạn, nợ xấu tăng lên thì dự phòng rủi ro của ngân hàng cũng sẽ tăng mạnh, tác động đến lợi nhuận ngân hàng. Duca và McLaughlin (1990), Sufian và Chong (2008) cho thấy tỉ lệ dự phòng rủi ro tín dụng so với tổng tín dụng càng cao thì lợi nhuận ngân hàng càng thấp.

Ngày nay, bên cạnh hoạt động tín dụng, huy động vốn thì các sản phẩm dịch vụ khác của Ngân hàng không ngừng phát triển cả về số lượng và chất lượng. Tỷ lệ thu nhập ngoài lãi càng lớn thể hiện mức độ đa dạng hóa các sản phẩm dịch vụ khác ngoài tín dụng cũng như hiệu quả của các sản phẩm dịch vụ này. Nó cũng đồng nghĩa với việc phân tán rủi ro trong hoạt động kinh doanh của ngân hàng (Hoàng Ngọc Tiến và Võ Thị Hiền, 2010). Kết quả nghiên cứu của Lê Long Hậu và Phạm Xuân Quỳnh (2016) đã cho thấy đa dạng hóa thu nhập, tăng tỷ lệ thu nhập thuần ngoài lãi là có lợi cho các NHTM Việt Nam vì giúp tăng khả năng sinh lời cũng như hiệu quả kinh doanh ngân hàng.

Cuối cùng, nguồn vốn trong kinh doanh đóng vai trò là nguồn lực của doanh nghiệp, ngân hàng. Tỷ lệ vốn chủ sở hữu trên tổng tài sản đo lường tình trạng đủ vốn, nguồn lực cũng như sự an toàn và lành mạnh của một ngân hàng. Vốn chủ sở hữu cao sẽ tạo điều kiện mở rộng chi nhánh, đầu tư công nghệ ngân hàng. Do đó, tỷ lệ vốn chủ sở hữu trên tổng tài sản càng cao thì lợi nhuận ngân hàng sẽ càng cao.

\section{Các nhân tố bên ngoài}

Tăng trưởng kinh tế là một trong những chỉ số kinh tế vĩ mô đặc biệt quan trọng và nó thường được đo bằng sự tăng trưởng tổng sản phẩm quốc dân (GNP) hoặc tổng sản phẩm quốc nội (GDP). Anbar và Alper (2011) cho rằng các ngân hàng thường hưởng lợi nhiều hơn từ các nền kinh tế tăng trưởng cao hơn bằng cách cho vay nhiều hơn và tăng chất lượng tài sản ngân hàng. Kết quả nghiên cứu trước đây đều cho thấy mối quan hệ tích cực giữa tăng trưởng kinh tế và lợi nhuận ngân hàng Sufian và Chong (2008); Trần Huy Hoàng và Nguyễn Hữu Huân (2016).

Lạm phát gây ra sự biến động lớn đối với nền kinh tế. Một số nghiên cứu đã chỉ ra mối quan hệ ngược chiều giữa lạm phát và lợi nhuận của ngân hàng như Sufian và Chong (2008). Tuy nhiên, các nghiên cứu khác 
chỉ ra mối quan hệ tỷ lệ thuận giữa lạm phát và lợi nhuận của ngân hàng. Tan và Floros (2012); Sastrosuwito và Suzuki (2012), Đặng Hữu Mẫn, Hoàng Dương Việt Anh (2014).

\section{PHƯƠNG PHÁP NGHIÊN CÚU}

\subsection{Dữ liệu}

Nghiên cứu thu thập dữ liệu thứ cấp từ các báo cáo tài chính đã được kiểm toán hàng năm của các 9 ngân hàng thương mại cổ phần được niêm yết trên sàn Hose và Hnx trong giai đoạn 2009 đến 2016. Các ngân hàng khác không đủ dữ liệu trong khoản thờig ian nghiên cứu sẽ bị loại bỏ. Các thông tin được thu thập gồm: tổng tài sản, thu nhập sau thuế, doanh thu thuần, vốn chủ sỡ hữu, dự phòng rủi ro tín dụng, dư nợ cho vay, thu nhập ngoài lãi, chi phí ngoài lãi. Bên cạnh đó, các yếu tố bên ngoài gồm GDP và lạm phát hàng năm; được thu thập từ Tổng Cục thống kê Việt Nam.

\subsection{Mô hình nghiên cứu}

$\boldsymbol{R O A}=\beta(1)+\beta(2) * \mathrm{INFL}+\beta(3) * \mathrm{GDP}+\beta(4) * \mathrm{LNTA}+\beta(5) *$ Risk $+\beta(6) * \mathrm{NII}+\beta(7) * \mathrm{NIE}+$ $\beta(8) * \mathrm{EQASS}+\varepsilon \mathrm{i}, \mathrm{t}$

Bảng 1: Các biến nghiên cứu

\begin{tabular}{|c|c|c|c|c|c|}
\hline STT & Biến & Ý nghĩa & Đo lương & Tác đông & Các nghiên cứu \\
\hline \multicolumn{6}{|c|}{ Biến phụ thuộc } \\
\hline 1 & ROA & $\begin{array}{l}\text { Lợi nhuận ngân } \\
\text { hàng }\end{array}$ & ROA $=\frac{\text { Lợi nhuận sau thuế }}{\text { Tổng tài sản bình quân }}$ & & $\begin{array}{l}\text { Ben Naceur và Goaied } \\
\text { (2009); Sufian và } \\
\text { Chong (2008) }\end{array}$ \\
\hline \multicolumn{6}{|c|}{ Biến độc lập } \\
\hline \multicolumn{6}{|c|}{ Biến bên trong } \\
\hline 2 & Size & $\begin{array}{l}\text { Qui mô ngân } \\
\text { hàng }\end{array}$ & Size $=\log ($ Tổng tài sản $)$ & + & $\begin{array}{l}\text { Athanasogloi và công } \\
\text { sự (2006); Trần Huy } \\
\text { Hoàng, Nguyễn Hữu } \\
\text { Huân (2016) }\end{array}$ \\
\hline 3 & Risk & Rủi ro tín dụng & Risk $=\frac{\text { Dự phòng rủi ro tín dụng }}{\text { Tổng tín dụng }}$ & - & $\begin{array}{lll}\text { Sufian } & \text { và } & \text { Chong } \\
(2008)\end{array}$ \\
\hline 4 & NII & $\begin{array}{l}\text { Tỷ lệ thu nhập } \\
\text { ngoài lãi }\end{array}$ & $\mathrm{NII}=\frac{\text { Thu nhập ngoài lãi }}{\text { Tổng tài sản }}$ & + & $\begin{array}{l}\text { Hoàng Ngọc Tiến và } \\
\text { Võ Thị Hiền, 2010; Lê } \\
\text { Long Hậu và Phạm } \\
\text { Xuân Quỳnh (2016) }\end{array}$ \\
\hline 5 & NIE & $\begin{array}{l}\text { Tỷ lệ chi phí } \\
\text { ngoài lãi }\end{array}$ & NIE $=\frac{\text { Chi phí ngoài lãi }}{\text { Tổng tài sản }}$ & $+/-$ & $\begin{array}{lll}\text { Sufian } & \text { và } & \text { Chong } \\
(2008) & & \end{array}$ \\
\hline 6 & EQASS & Cấu trúc vốn & EQASS $=\frac{\text { Vốn chủ sở hữu }}{\text { Tổng tài sản }}$ & + & $\begin{array}{lll}\text { Sufian } & \text { và } & \text { Chong } \\
(2008) & & \end{array}$ \\
\hline \multicolumn{6}{|c|}{ Biến bên trong } \\
\hline 7 & GDP & $\begin{array}{l}\text { Tăng trưởng kinh } \\
\text { tế }\end{array}$ & $\mathrm{GDP}=\log (\mathrm{GDP})$ & + &  \\
\hline 8 & INFL & Lạm phát & Tỷ lệ lạm phát hàng năm & $+/-$ & $\begin{array}{l}\text { Đặng Hữu Mẫn, Hoàng } \\
\text { Dương Việt Anh } \\
\text { (2014); Lê Long Hậu } \\
\text { và Phạm Xuân Quỳnh } \\
\text { (2016) }\end{array}$ \\
\hline
\end{tabular}




\section{KẾT QUẢ NGHIÊN CÚU}

\subsection{Thống kê mô tả các biến nghiên cứu}

Tổng số công ty nghiên cứu là 9 . Tổng số quan sát là 72 . Giá trị lớn nhất, giá trị nhỏ nhất, giá trị trung bình và độ lệch chuẩn các biến nghiên cứu được trình bày ở Bảng 2 . Bảng 2 cho thấy tăng trưởng kinh tế có giá trị lớn nhất, lợi nhuận có giá trị thấp nhất trong tất cả các biến.

Bảng 2: Thống kê mô tả các biến nghiên cứu

\begin{tabular}{|l|c|c|c|c|c|c|c|c|}
\hline & ROA & Size & Risk & NIE & NII & EQASS & GDP & INFL \\
\hline Mean & 0.0087 & 8.2749 & 0.0141 & 0.0190 & 0.0062 & 0.0803 & 9.4649 & 0.0706 \\
\hline Median & 0.0090 & 8.2710 & 0.0120 & 0.0159 & 0.0066 & 0.0761 & 9.5349 & 0.0628 \\
\hline Max & 0.0173 & 9.0028 & 0.0331 & 0.0595 & 0.0203 & 0.2040 & 9.6532 & 0.1858 \\
\hline Min & 0.0001 & 7.2716 & 0.0081 & 0.0052 & -0.0058 & 0.0425 & 9.0782 & 0.0063 \\
\hline Std. Dev. & 0.0047 & 0.4205 & 0.0055 & 0.0099 & 0.0041 & 0.0259 & 0.1847 & 0.0529 \\
\hline Skewness & -0.2642 & -0.5798 & 1.4915 & 2.2873 & 0.1751 & 1.8225 & -0.9951 & 0.9076 \\
\hline Kurtosis & 2.2126 & 3.0031 & 5.0539 & 8.4960 & 4.3653 & 9.0559 & 2.8014 & 2.9891 \\
\hline N & 72 & 72 & 72 & 72 & 72 & 72 & 72 & 72 \\
\hline
\end{tabular}

\subsection{Các nhân tố tác động đến lợi nhuận của ngân hàng thương mại}

Bảng 3 trình bày kết quả hồi qui dữ liệu bảng với tác động cố định và tác động ngẫu nhiên. Kết quả cho thấy giá trị $F=16,4$ và $p=0,000$ cho thấy mô hình có ý nghĩa, hệ số $\mathrm{R} 2$ điều chỉnh $=0,765$ cho thấy $76,5 \%$ biến thiên của lợi nhuận của ngân hàng được giải thích được các biến độc lập. Bên cạnh đó, các biến nghiên cứu đều có tác động dương và có ý nghĩa ở mức $1 \%$ ngoại trừ biến rủi ro tín dụng. Thu nhập ngoài lãi có hệ số hồi qui là 0,412882 với mức $\mathrm{p}=0.0007<1 \%$, chứng tỏ thu nhập ngoài lãi càng tăng thì lợi nhuận của ngân hàng càng cao. Đây cũng là biến nghiên cứu có hệ số hồi qui lớn nhất. Điều này cho thấy các ngân hàng thương mại nên đa dạng hóa danh mục sản phẩm phi truyền thống để gia tăng lợi nhuận của ngân hàng. Bên cạnh đó, chi phí ngoài lãi cũng có tác động cùng chiều với lợi nhuận. Chi phí ngoài lãi còn thể hiện chất lượng nguồn lực mà ngân hàng phải trả để cung cấp dịch vụ cho khách hàng. Với đặc thù nền kinh tế phát triển cao về cạnh tranh nhân lực, tăng chi phí lương thưởng, phụ cấp, các hoạt động quản bá thương hiệu hiệu quả trong điều kiện các yếu tố khác không đổi sẽ thúc đẩy lợi nhuận của ngân hàng. Qui mô ngân hàng và tỷ lệ vốn chủ sở hữu trên tổng tài sản có tác động dương đến kết quả hoạt động kinh doanh của ngân hàng. Rủi ro tín dụng có hệ số hồi qui là -0.088705 cho thấy tác động ngược chiều với lợi nhuận. Kết quả nghiên cứu phù hợp với giả thiết đã đưa ra và kết quả các nghiên cứu đi trước Sufian và Chong (2008); Trần Huy Hoàng, Nguyễn Hữu Huân (2016). Các biến bên ngoài như tăng trưởng kinh tế và lạm phát có tác động dương và có ý nghĩa ở mức $1 \%$ với lợi nhuận của ngân hàng thương mại. Kết quả này phù hợp với các nghiên cứu đi trước Đặng Hữu Mẫn, Hoàng Dương Việt Anh (2014); Lê Long Hậu và Phạm Xuân Quỳnh (2016).

Bảng 3: Hệ số hồi qui

\begin{tabular}{|c|c|c|c|c|}
\hline & \multicolumn{2}{|c|}{ Tác động cố định } & \multicolumn{2}{c|}{ Tác động ngẫu nhiên } \\
\hline Biến & Hệ số hồi quy & Thống kê t & Hệ số hồi qui & Thống kê t \\
\hline Hằng số & 0.048981 & 2.117614 & 0.051346 & 2.284314 \\
\hline Biến bên trong & & & & \\
\hline Size & $0.008374^{* * *}$ & 2.507725 & $0.006066^{* * *}$ & 2.717435 \\
\hline Risk & -0.088705 & -0.966244 & -0.097068 & -1.185814 \\
\hline NII & $0.412882^{* * *}$ & 3.590868 & $0.415098^{* * *}$ & 3.669589 \\
\hline NIE & $0.090442^{* *}$ & 2.230847 & $0.074331^{* *}$ & 1.902532 \\
\hline EQASS & $0.043329^{* * *}$ & 2.647037 & $0.041032^{* * *}$ & 2.650279 \\
\hline Biến bên ngoài & & & & 3.530870 \\
\hline GDP & $0.012485^{* * *}$ & 3.530290 & $0.010655^{* * *}$ & 4.743418 \\
\hline INFL & $0.029476^{* * *}$ & 4.709459 & $0.029639^{* * *}$ & 0.003018 \\
\hline F & 16,4 & & 22.35572 & 0.006248 \\
\hline R2 điều chỉnh & 0,765 & & 0.677990 & \\
\hline
\end{tabular}

Với mức ý nghĩa $1 \%, 5 \%$ và $10 \%$ thể hiện $* * *, * *$ và * 


\subsection{Một số kiểm định khác}

\subsubsection{Tư tuong quan}

Bảng 4: Breusch-Godfrey Serial Correlation LM

\begin{tabular}{|l|r|l|r|}
\hline F-statistic & 9.817848 & Prob. F(2,62) & 0.0002 \\
\hline Obs*R-squared & 17.31804 & Prob. Chi-Square(2) & 0.0002 \\
\hline
\end{tabular}

Kết quả cho thấy giá trị $\mathrm{F}=9,8$ với $\mathrm{p}=0,0002$, điều đó cho thấy có sự tự tương quan trong mô hình nghiên cứu

\subsubsection{Phương sai thay đổi}

Bảng 5: Heteroskedasticity Test: White

\begin{tabular}{|l|r|l|r|}
\hline F-statistic & 1.368319 & Prob. F(35,36) & 0.1767 \\
\hline Obs*R-squared & 41.10282 & Prob. Chi-Square(35) & 0.2208 \\
\hline Scaled explained SS & 27.48511 & Prob. Chi-Square(35) & 0.8134 \\
\hline
\end{tabular}

Bảng 5 cho thấy giá trị $\mathrm{F}=1,3683$ với giá trị $\mathrm{p}=0,17$ chứng tỏ không có phương sai thay đổi.

\section{KẾT LUÂN}

Ngân hàng có vai trò rất quan trọng trong nền kinh tế. Nghiên cứu phân tích các nhân tố ảnh hưởng đến lợi nhuận của ngân hàng thương mại cổ phần Việt Nam trong giai đoạn 2009-2016. Sử dụng hồi quy dữ liệu bảng, kết quả đã cho thấy qui mô ngân hàng, thu nhập ngoài lãi, cấu trúc vốn, tăng trưởng kinh tế và lạm phát tác động tích cực đến lợi nhuận ngân hàng. Dựa vào kết quả nghiên cứu, bài viết đề xuất một số khuyến nghị nhằm gia tăng lợi nhuận của hệ thống ngân hàng thương mại Việt Nam trong thời gian sắp tới.

Thư nhất, cung cấp danh mục sản phẩm dịch vụ đa dạng: Các ngân hàng nên mở rộng danh mục sản phẩm dịch vụ và cung cấp nhiều dịch vụ hơn cho khách hàng hiện hành. Bên cạnh thu hút khách hàng mới thì ngân hàng nên thúc đẩy bán sản phẩm dịch vụ nhiều hơn cho khách hàng hiện hành. Khi đó, ngân hàng sẽ là nơi mà khách hàng thực hiện tất cả những giao dịch từ thanh toán, tiết kiệm, tín dụng đầu tư, tiêu dùng, mua sắm trực tuyến...

Thư hai, tiếp tục hiện đại hóa công nghệ ngân hàng: cách mạng công nghệ 4.0 sẽ đem đến rất nhiều cơ hội cho hoạt động ngân hàng như sự phát triển nhanh của hoạt động mua sắm và thanh toán trực tuyến. Do đó, các ngân hàng phải đẩy mạnh ứng dụng công nghệ ngân hàng hiện đại, mở rộng và cung cấp các dịch vụ thanh toán điện tử, góp phần giảm chi phí, thời gian giao dịch, tăng năng suất lao động.

Thú $b a$, tăng quy mô và sử dụng hiệu quả vốn chủ sở hữu: tăng vốn chủ sở hữu là yêu cầu thường xuyên từ chính ngân hàng cũng như từ cơ quan quản lý do đặc thù của ngành. Quy mô vốn chủ sở hữu cũng là tiêu chí để đánh giá đự lớn mạnh của ngân hàng. Các ngân hàng có vốn chủ sở hữu lớn thì sẽ có điều kiện tăng tài sản, đầu tư công nghệ và mở rộng chí nhánh, tiếp cận khách hàng.

\section{TÀI LIỆ THAM KHẢO}

1. Anbar, A., \& Alper, D. (2011). Bank specific and macroeconomic determinants of commercial bank profitability: Empirical evidence from Turkey.

2. Athanasoglou, P. P., Brissimis, S. N., \& Delis, M. D. (2008). Bank specific, industry specific and macroeconomic determinants of bank profitability. Journal of International Financial Markets, Institutions and Money 18(2), $121-136$.

3. Ben Naceur, S., \& Goaied, M. (2008). The determinants of commercial bank interest margin and profitability: Evidence from Tunisia. Frontiers in Finance and Economics 5(1), 106-130.

4. Cẩm An, 2015. Kinh tế Việt Nam đã thay đổi như thế nào khi gia nhập WTO? Truy cập từ http://cafef.vn/vi-modau-tu/kinh-te-viet-nam-da-thay-doi-nhu-the-nao-khi-gia-nhap-wto-20150918113948454.chn

5. Chính phủ, 2006. Nghị định số 141/2006/NĐ-CP về ban hành danh mục mức vốn pháp định của các tổ chức tín dụng. Truy cập từ https://thuvienphapluat.vn/van-ban/Tien-te-Ngan-hang/Nghi-dinh-141-2006-ND-CP-Danhmuc-muc-von-phap-dinh-to-chuc-tin-dung-15649.aspx.

6. Đặng Hữu Mẫn, Hoàng Dương Việt Anh, Nghiên cứu các yếu tố kinh tế và thể chế ảnh hưởng đến hoạt động của hệ thống ngân hàng thương mại Việt Nam, KT\&PT, số 209 tháng 11 năm 2014, tr. 82-94 
7. Duca, J., \& McLaughlin, M. (1990). Developments affecting the profitability of commercial banks. Federal Reserve Bulletin, 477-499.

8. Hoàng Ngọc Tiến và Võ Thị Hiền (2010). Trao đổi về phương pháp tính tỷ lệ thu nhập ngoài tín dụng của ngân hàng thương mại. Tạp chí Công nghệ Ngân hàng, 48,36-39;

9. Lê Long Hậu và Phạm Xuân Quỳnh (2016). Tác động của đa dạng hóa thu nhập đến hiệu quả kinh doanh của các Ngân hàng thương mại Việt Nam. Tạp chí Công nghệ Ngân hàng, 124, 11-22;

10. Miller, S. M., \& Noulas, A. (1997). Portfolio mix and large bank profitability in the USA. Applied Economics 29, 505-512.

11. Ngân hàng nhà nước, 2014. Thông tư Số: 36/2014/TT-NHNN quy định các giới hạn, tỷ lệ bảo đảm an toàn trong hoạt động của tổ chức tín dụng, chi nhánh ngân hàng nước ngoài. Truy cập từ https://thuvienphapluat.vn/vanban/Tien-te-Ngan-hang/Thong-tu-36-2014-TT-NHNN-gioi-han-ty-le-bao-dam-an-toan-hoat-dong-to-chuc-tindung-chi-nhanh-ngan-hang-nuoc-ngoai-258000.aspx

12. Ngân hàng nhà nước, 2016. Thông tư Số: 41/2016/TT-NHNN quy định tỷ lệ an toàn vốn đối với ngân hàng, chi nhánh ngân hàng nước ngoài. Truy cập từ https://luatvietnam.vn/tai-chinh/thong-tu-41-2016-tt-nhnn-ngan-hangnha-nuoc-viet-nam-111599-d1.html

13. Nguyễn Xuân Thành, 2016. Ngân hàng thương mại Việt Nam: Từ những thay đổi về luật và chính sách giai đoạn 2006-2010 đến các sự kiện tái cơ cấu giai đoạn 2011-2015. http://www.fetp.edu.vn/vn/bao-cao-chinh-sach/nganhang-thuong-mai-viet-nam-tu-nhung-thay-doi-ve-luat-va-chinh-sach-giai-doan-20062010-den-cac-su-kien-taico-cau-giai-doan-20112015.

14. Sufian, F., \& Chong, R. R. (2008). Determinants of bank profitability in a developing economy: empirical evidence from the Philippines. Asian Academy of Management Journal of Accounting \& Finance, 4(2).

15. Tổng Cục Thống kê, 2017. Tổng sản phẩm quốc nội và tỷ lệ lạm phát hàng năm của Việt Nam.

16. Trần Huy Hoàng và Nguyễn Hữu Huân (2016). Phân tích các yếu tố tác động đến hiệu quả hoạt động của hệ thống ngân hàng thương mại Việt Nam trong thời kỳ hội nhập tài chính quốc tế. Tạp chí science \& technology development, Vol 19, No Q1 - 2016, p 88-101. 